\title{
Insight into Hyper-Branched Aluminum Phosphonate in Combination with Multiple Phosphorus Synergies for Fire-Safe Epoxy Resin Composites
}

\author{
Yao Yuan ${ }^{1}$, Bin Yu ${ }^{2}$, Yongqian Shi ${ }^{3}{ }^{\circledR}$, Long Mao ${ }^{1}$, Jianda Xie ${ }^{1}$, Haifeng Pan ${ }^{4}$, Yuejun Liu ${ }^{1, *}$ \\ and Wei Wang ${ }^{5, *(1)}$ \\ 1 Fujian Provincial Key Laboratory of Functional Materials and Applications, School of Materials Science and \\ Engineering, Xiamen University of Technology, Xiamen 361024, China; yuanyao@mail.ustc.edu.cn (Y.Y.); \\ maolong0412@163.com (L.M.); xiejianda@xmut.edu.cn (J.X.) \\ 2 Centre for Future Materials, University of Southern Queensland, Toowoomba, QLD 4350, Australia; \\ ahu07yb@gmail.com \\ 3 College of Environment and Resources, Fuzhou University, Fuzhou 350002, China; shiyq1986@fzu.edu.cn \\ 4 Faculty of Engineering, China University of Geosciences (Wuhan), Wuhan 430074, Hubei, China; \\ hfpan19@163.com \\ 5 State Key Laboratory of Fire Science, University of Science and Technology of China, Hefei 230026, China \\ * Correspondence: yjliu_2005@126.com (Y.L.); wwei433@mail.ustc.edu.cn (W.W.)
}

Received: 26 November 2019; Accepted: 13 December 2019; Published: 1 January 2020

\begin{abstract}
Epoxy resin (EP) has widespread applications in thermosetting materials with great versatility and desirable properties such as high electrical resistivity and satisfactory mechanical properties. At present, 9,10-Dihydro-9-oxa-10-phosphaphenanthrene-10-oxide (DOPO) is widely applied to EP matrix for high flame resistance. Nevertheless, EP/DOPO composites acquire highly toxic decomposition products and smoke particles produced during combustion due to the gaseous fire-inhibition mechanism, which will be a major problem. To address this concern, an effective hyper-branched aluminum phosphonate (AHPP) was rationally designed and then coupled with DOPO into EP matrix to fabricate the fire-safe epoxy resin composites. On the basis of the results, significant increment in limiting oxygen index value (an achievement of $32 \%$ from $23.5 \%$ for pristine $\mathrm{EP})$ and reduction in peak heat release rate and total heat release $(59.4 \%$ and $45.6 \%)$ with the DOPO/AHPP ratio of 2:1 were recorded. During the cone calorimeter test, both the smoke production and total CO yield of EP-4 composite with the DOPO/AHPP ratio of 1:2 were dramatically decreased by $42.7 \%$ and $53.6 \%$, which was mainly associated with the excellent catalytic carbonization of AHPP submicro-particles for EP composite. Future applications of submicro-scaled flame-retardant with various phosphorus oxidation states will have good prospects for development.
\end{abstract}

Keywords: epoxy resin; hyper-branched flame-retardant; smoke suppression; mechanism

\section{Introduction}

Epoxy resin (EP) belongs to an outstanding class of thermosetting polymers, which has been considered to be a widely used material owing to its multiple and unique properties, for instance low shrinkage, superior solvent resistance, remarkable electrical insulation, excellent adhesive strength and ease of curing and processing [1-4]. Nonetheless, as an organic polymer material, EP produces toxic fumes (especially $\mathrm{CO}$ ) and soot particles (smoke) during the combustion process, which greatly damages our natural environment and seriously restricts its potential applications in aerospace, coating, and electrical device fields [5-8]. Accordingly, under safety consideration, incorporating appropriate 
synergists to fabricate the fire-safe epoxy resin composites is an urgent and challenging issue for fire safety design [9-11].

In the past few years, different approaches have been proposed by introducing various halogen-free flame retardants containing phosphorus, nitrogen, and silicon into the EP composites without environmental issues [12-14]. Generally, phosphorus-containing flame-retardant is considered to be the most efficient method among the above systems [15,16]. Notably, 9,10-Dihydro-9-oxa-10-phosphaphenanthrene-10-oxide (DOPO) has been commercially applied in various polymer materials, especially EPs [17,18]. The DOPO structure was covalently incorporated into the backbones of EPs by the reaction between P-H bond and epoxy groups, which greatly increases the dispersion and durability of the flame-retardant. Unfortunately, highly toxic decomposition products and soot particles generated under fire conditions are the critical defects of the flame-retardant. Qiu et al. [19] demonstrated that the simultaneous existence of TDBA (phosphaphenanthrene derivative) and DOPO structure in the EP composites produced more pyrolysis products and formed large-scale smoke particles, signifying the prominent gas phase action of DOPO present in inhibiting the transformation of the matrix to fuel.

On the basis of previous investigation, the chemical environment of phosphorus affects its flame-retardant efficiency. Braun et al. [20] compared the effect of phosphorus valence on the fire behavior of EP and found that the flame inhibition effect, i.e., gas phase action decreased with the increasing oxidation state. Generally, flame retardants with a higher oxidation state show only condensed phase action compared to the lower oxidation state, which mainly functions in the gas phase [21]. Unfortunately, there are still no reports on the phosphorus-containing flame-retardant EP composites with the combined effects of various oxidation states. Furthermore, a large amount of research on phosphorus-based additives with various phosphorus-containing groups in different valence should be attractive for advanced application.

Potentially owning phosphorus-rich groups, hyper-branched polymers possess interesting architecture and a large number of active terminal groups compared to their linear counterparts [22,23], and have attracted increasing attention in constructing highly-efficient flame retardants. Traditionally, hyper-branched polymers are prepared mainly by polymerization of $\mathrm{A}_{2}+\mathrm{B}_{3}$, and have received a lot of attention for the unusual architecture and physicochemical properties [24]. Meanwhile, aluminum salts have attracted great interest recently due to their practical advantages such as facile preparation, being easy to handle, none of the toxic gas, and no health safety and environmental impacts. Yang et al. $[25,26]$ incorporated aluminum hypophosphite (AHP), melamine, and polycarbonate into reinforced poly(1,4-butylene terephthalate), showing excellent flame retardance and reaching UL 94 V-0 criterion, while in neither study was the smoke hazard of PBT composites taken into consideration. Pinto et al. [26] prepared flame-retardant thermoplastic polyurethane elastomer composites using aluminum hydroxide (ATH), which offers the advantage of acting as flame-retardant as well as a smoke suppressant. However, 70 wt. \% loading is still too high.

To obtain EP composites with simultaneous excellent flame retardance and smoke hazard suppression, a novel and submicro-scaled hyper-branched aluminum phosphonate (AHPP) was successfully prepared. The chemical structures of the precursor and the final product were confirmed by a great deal of structural characterization and morphologic assessments. This work extends a new path for providing the synergistic effect between AHPP and DOPO with various oxidation states $(-1$, $+1,+3)$ on improving smoke suppression and fire safety for polymeric materials during combustion. Furthermore, the flame retardation and smoke suppression mechanisms were also systematically studied through various measurements. The detailed characterization information is supplied in the Supporting Information. 


\section{Materials and Methods}

\subsection{Raw Materials}

Diglycidyl ether of bisphenol A (DGEBA, E-44, epoxy value $=0.44 \mathrm{~mol} / 100 \mathrm{~g}$ ) was purchased from Jiangfeng Chemical Industry Co. Ltd. (Hefei, China). Benzene phosphorus oxydichloride (BPOD) and DOPO were obtained from Sun Chemical Technology Co., Ltd. (Shanghai, China). 4, 4'-diaminodiphenylmethane (DDM), hydrogen peroxide (30\% aq.), barium hydroxide (analytical reagent grade), acetone, aluminum sulfate $\left(\mathrm{Al}_{2}\left(\mathrm{SO}_{4}\right)_{3} \cdot 18 \mathrm{H}_{2} \mathrm{O}\right)$, and Tetrakis(hydroxymethyl)phosphonium sulfate (THPS, technical pure grade) were purchased from Sinopharm Chemical Reagent Co. Ltd. (Shanghai, China).

\subsection{Synthesis of the Precursor}

Tris(hydroxymethyl)phosphine oxide (THPO) was prepared according to our previous work [27] and the preparation process of the precursor was successfully prepared (see Figure 1). All of the raw materials are nontoxic and environment-friendly. In a typical experiment, a three-necked flask was charged with $0.3 \mathrm{~mol}$ of BPOD under stirring, followed by slowly adding $0.15 \mathrm{~mol}$ of THPO to the suspension. The polymerization was carried out at $100^{\circ} \mathrm{C}$ for $4 \mathrm{~h}$ with constant agitation under nitrogen. A white solid with a ca. $98 \%$ yield was obtained after the purification of the hyper-branched phosphonate (HPP).

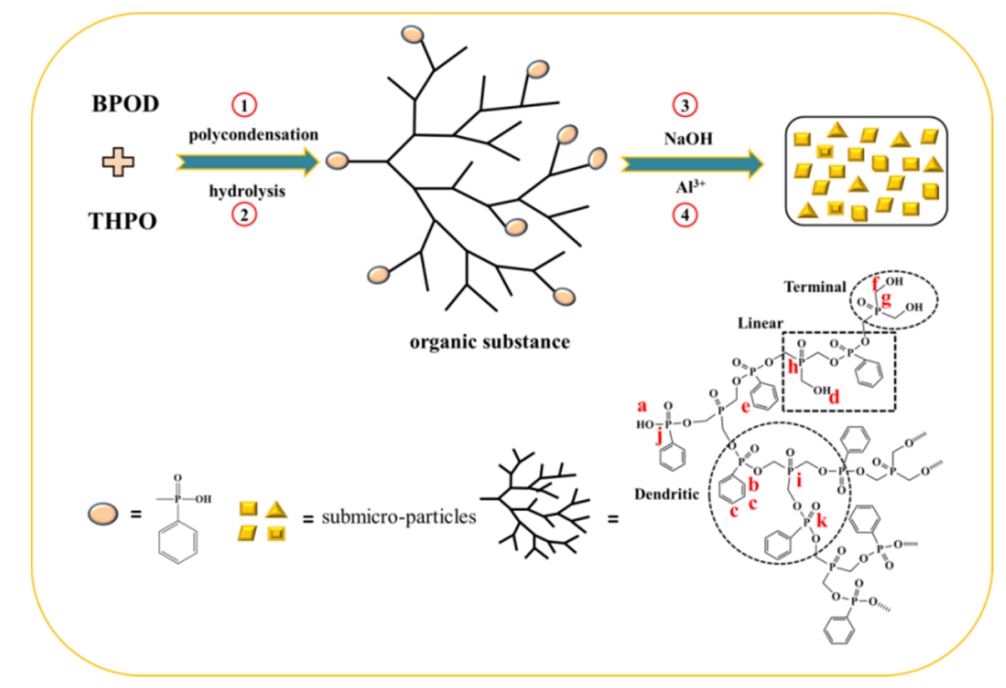

Figure 1. Synthetic route of hyper-branched aluminum phosphonate (AHPP) via the dehydrochlorination of tris(hydroxymethyl)phosphine oxide (THPO) with benzene phosphorus oxydichloride (BPOD).

\subsection{Synthesis of AHPP Submicro-Particles}

The precursor was dissolved in $50 \mathrm{~mL} \mathrm{H}_{2} \mathrm{O}$ under stirring in a three-necked flask. A standardized sodium hydroxide solution $(0.1 \mathrm{M})$ was added, grown at $\mathrm{pH} 7.5-8$. While the mixture turned colorless sticky liquid, $0.05 \mathrm{~mol}$ of aluminum sulfate was dissolved in $20 \mathrm{~mL} \mathrm{H}_{2} \mathrm{O}$ and dripped into the reaction system at $70{ }^{\circ} \mathrm{C}$ for $20 \mathrm{~min}$. After cooling to room temperature within another $30 \mathrm{~min}$, more white granules appeared. Successively, the resulting products, i.e., hyper-branched aluminum phosphonate (AHPP), were washed and filtrated with water several times. The final products were dried at $100{ }^{\circ} \mathrm{C}$ and the yields were $>90.0 \%$. 


\subsection{Fabrication of EP/DOPO-AHPP Composites}

AHPP was firstly mixed into DGEBA and dispersed in acetone, followed by adequate mechanical stirring at $90^{\circ} \mathrm{C}$ for $1 \mathrm{~h}$. DDM was poured into the mixture after removing the solvent. Subsequently, it was added to the preheated mold, curing at $100{ }^{\circ} \mathrm{C}$ for $2 \mathrm{~h}$ and post-curing at $150{ }^{\circ} \mathrm{C}$ for another $2 \mathrm{~h}$. After cooling, the EP composites with AHPP and DOPO were labeled as EP/AHPP/DOPO in various proportions using this similar procedure and the formulations of EP samples are presented in Table 1.

Table 1. The formulations of pristine epoxy resin (EP) and its composites.

\begin{tabular}{ccccccc}
\hline Samples & EP (g) & DDM (g) & DOPO (g) & AHPP (g) & $\begin{array}{c}\text { Proportion } \\
\text { (DOPO/AHPP) }\end{array}$ & Additive Loading (wt. \%) \\
\hline EP-1 & 100 & 21.8 & - & - & - & - \\
EP-2 & 100 & 21.8 & 6.41 & - & - & 5 \\
EP-3 & 100 & 21.8 & 4.27 & 2.13 & $2 / 1$ & 5 \\
EP-4 & 100 & 21.8 & 2.13 & 4.27 & $1 / 2$ & 5 \\
EP-5 & 100 & 21.8 & 3.21 & 3.21 & $1 / 1$ & 5 \\
EP-6 & 100 & 21.8 & - & 6.41 & - & \\
\hline
\end{tabular}

\section{Results and Discussion}

\subsection{Structural Characterizations}

Submicro-scaled hyper-branched aluminum phosphonate (AHPP) was synthesized via the dehydrochlorination between $-\mathrm{OH}$ in THPO and $\mathrm{O}=\mathrm{P}-\mathrm{Cl}$ in BPOD. The chemical structure of the precursor was determined by the NMR spectrum at first. Figure S1a (Supplementary Materials) presents the multiplets in the ranges of 7.57-8.30 ppm and 7.39-7.51 ppm, corresponding to aromatic rings. The signal from $10.45 \mathrm{ppm}$ is characteristic of the hydroxy proton of $\mathrm{O}=\mathrm{P}-\mathrm{OH}$ and the peak at $5.5 \mathrm{ppm}$ is ascribed to the hydroxy proton of $\mathrm{P}-\mathrm{CH}_{2}-\mathrm{OH}$. Additionally, the chemical shift at 3.99 to $4.24 \mathrm{ppm}$ are characteristic of the methylene proton of $\mathrm{Ph}-\mathrm{P}(=\mathrm{O})-\mathrm{O}-\mathrm{CH}_{2}-\mathrm{P}=\mathrm{O}$. As depicted in Figure S1b (Supplementary Materials), the signal at $16.8 \mathrm{ppm}$ is associated with the phosphorus of $\mathrm{O}-(\mathrm{Ph}) \mathrm{P}(=\mathrm{O})-\mathrm{O}$, and the peak at $13.7 \mathrm{ppm}$ is attributed to the phosphorus of $\mathrm{O}-\mathrm{P}=\mathrm{O}(\mathrm{Ph})-\mathrm{O}$. Three peaks located at 43.2, 40.4, and $37.4 \mathrm{ppm}$ are due to the phosphorus of $\mathrm{O}=\mathrm{P}-\left(\mathrm{CH}_{2}-\right)_{3}$ with one, two, and three hydroxyls reacted, respectively, which are designated as terminal (T), linear (L), and dendritic (D) units [28]. These results confirm that the precursor was synthesized successfully.

The structure of the target product is further confirmed by FTIR spectroscopy. As shown in Figure $2 \mathrm{~b}$, the emergence of absorption peaks is characteristic of several function groups, such as $\mathrm{O}-\mathrm{H}$ $\left(3415 \mathrm{~cm}^{-1}\right), \mathrm{C}-\mathrm{H}\left(2920,2850 \mathrm{~cm}^{-1}\right), \mathrm{P}-\mathrm{Ph}\left(1440 \mathrm{~cm}^{-1}\right)$, and $\mathrm{P}-\mathrm{CH}_{2}\left(690,750 \mathrm{~cm}^{-1}\right)$ [29]. The signal from $1150 \mathrm{~cm}^{-1}$ is attributed to the $\mathrm{P}=\mathrm{O}$ and $\mathrm{O}=\mathrm{P}-\mathrm{C}$ stretching modes. Furthermore, the stretching vibrations at 1635,1542 , and $1494 \mathrm{~cm}^{-1}$ are characteristic of the skeletal vibration in aromatic rings [30]. Notably, the peak at $1080 \mathrm{~cm}^{-1}$, which is ascribed to the P-O-C bond in AHPP, confirms the successful linkage between BPOD and THPO [31].

The surface morphology of the AHPP submicro-particles was observed by SEM and TEM, as shown in Figures S2 and S3 (Supplementary Materials). The fact that the AHPP particles are well-dispersed and uniform without agglomeration is remarkable. Moreover, EDX was also used to determine the surface elements of AHPP particles. The characteristic peaks of $\mathrm{P}, \mathrm{O}$, and $\mathrm{Al}$ have been detected in the EDX spectrum, further confirming the successful preparation. 
(a)

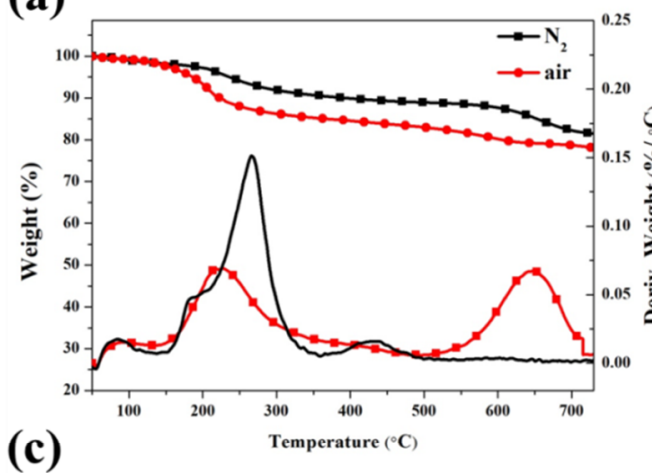

(c)

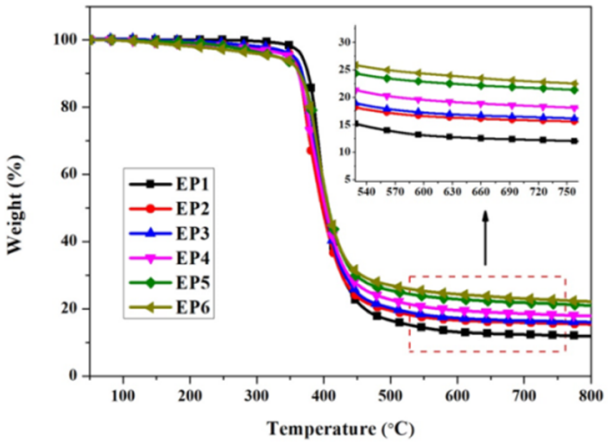

(b)
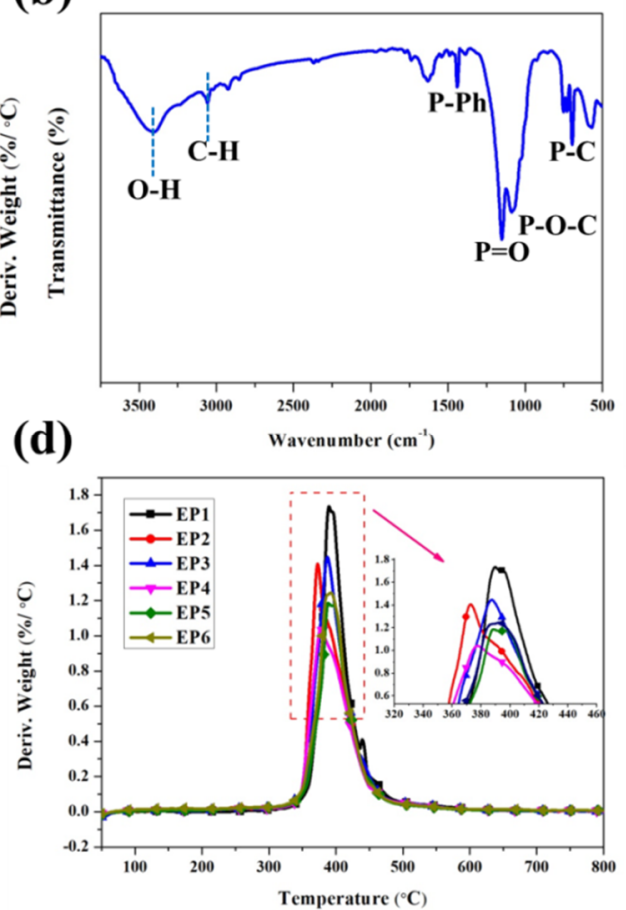

Figure 2. TGA and DTG curve of AHPP under nitrogen and air (a), FTIR spectrum (b) of AHPP, TGA (c) and DTG curves (d) of pristine EP and its composites under nitrogen.

\subsection{Characterization of the Degradation Behavior}

The thermal stability of pristine EP and its composites are depicted in Figure 2, and the corresponding thermograms of the resultant materials are summarized in Table 2. From the DTG curves, the cured epoxy and its composites display a single-step process by anaerobe decomposition (Figure 2d). Under nitrogen atmosphere, EP/DOPO or EP-AHPP induce lower $T_{d}$ value (EP: $367^{\circ} \mathrm{C}$, EP/DOPO: 279 ${ }^{\circ} \mathrm{C}$, EP-AHPP: $329^{\circ} \mathrm{C}$ ) and can be attributed primarily to the fact that the $\mathrm{O}=\mathrm{P}-\mathrm{O}$ and $\mathrm{P}-\mathrm{O}-\mathrm{C}$ bonds are more unstable than the normal $\mathrm{C}-\mathrm{C}$ bond [32]. By contrast, AHPP increases the number of char residues than DOPO does. Additionally, when AHPP and DOPO are introduced simultaneously into EP matrix in certain content, the EP/DOPO-AHPP system sustains initial decomposition temperature at high temperature and increases the volume of char residues at $800^{\circ} \mathrm{C}$. Ultimately, from the DTG curves, it is clear that significant improvement in thermal stability can be achieved by the simultaneous incorporation of AHPP and DOPO with higher char residue during combustion.

Table 2. TGA data for cured epoxy resin and its composites under $\mathrm{N}_{2}$ atmosphere.

\begin{tabular}{cccc}
\hline \multirow{2}{*}{ Samples } & \multicolumn{3}{c}{ Nitrogen } \\
\cline { 2 - 4 } & $\boldsymbol{T}_{\boldsymbol{d}}\left({ }^{\circ} \mathbf{C}\right)$ & $\boldsymbol{T}_{\max }\left({ }^{\circ} \mathbf{C}\right)$ & Char $(\%)$ \\
\hline EP-1 & 367 & 391 & 11.8 \\
EP-2 & 279 & 372 & 12.4 \\
EP-3 & 356 & 388 & 15.6 \\
EP-4 & 321 & 378 & 21.0 \\
EP-5 & 350 & 390 & 17.5 \\
EP-6 & 329 & 393 & 21.1 \\
\hline
\end{tabular}

Basically, RT-FTIR analysis provides useful information about the chemical structure changes to ascertain the degradation behavior of pristine EP, EP/DOPO, EP-AHPP, and EP/AHPP samples. The main peaks and bands of EP and its composites are shown in Figure 3a,b and Table S1 
(Supplementary Materials). As for the marked regions, it is very clear that the peaks at 3510, $2930,2860,1603,1502,1360,1110$, and $820 \mathrm{~cm}^{-1}$ belong to EP [33]. The intensity of the band at 2860 and $2930 \mathrm{~cm}^{-1}$ resulting from symmetric and $\mathrm{CH}_{2}$ asymmetric vibrations disappears completely at $550{ }^{\circ} \mathrm{C}$, indicating the main chain of the epoxy has been completely degraded during the heating process [34]. With the temperature increasing, only the absorption peaks at 1603,1502,1110, and $820 \mathrm{~cm}^{-1}$ are maintained, which could be attributed to the char residue with a multi-aromatic structure formed [35]. As a result, the $\mathrm{P}-\mathrm{O}-\mathrm{P}, \mathrm{P}-\mathrm{O}-\mathrm{C}$, and $\mathrm{O}=\mathrm{P}-\mathrm{O}-$ vibrations at 1250 and $1090 \mathrm{~cm}^{-1}$ for $\mathrm{EP}-2$ and $\mathrm{EP}-4$ are found in the FTIR spectra [36], signifying that the presence of AHPP or DOPO-AHPP results in the formation of protective residues during burning [37]. Accordingly, the result clearly indicates that the formation of char residue for the EP/DOPO-AHPP composites performs strong physical barriers during combustion to increase the fire safety of EP composites.
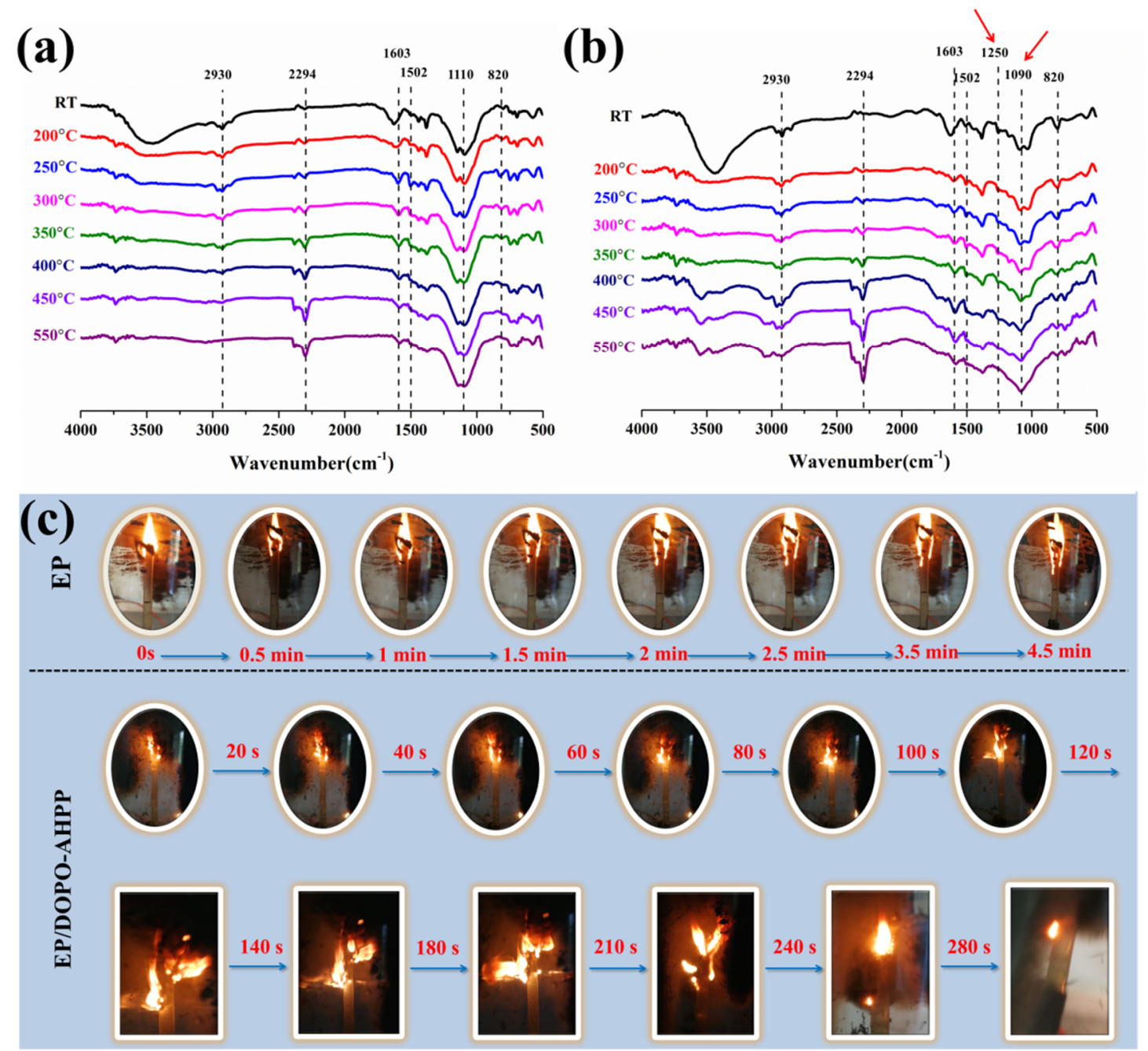

Figure 3. FTIR spectra of pristine EP (a), EP/DOPO-AHPP (b) at different pyrolysis temperatures, and video screenshots of pristine EP, EP/DOPO-AHPP at oxygen concentrations of $23.5 \%$ and $32 \%$ during LOI test (c).

\subsection{Flame Retardance}

The effect of phosphorus-containing flame retardants with various phosphorus oxidation states on the ignitability of pristine epoxy and its composites were investigated by LOI and vertical burning UL-94 test. As shown in Table 3, pristine EP has intrinsic flammability with LOI value of $23.5 \%$ and no classification during UL-94 tests. In comparison with the EP/DOPO or EP-AHPP sample, the LOI value 
of EP/DOPO-AHPP significantly increases. Specially, when the ratio of DOPO and AHPP is 2:1, the LOI value rises to $32 \%$. Moreover, the cured EP/DOPO-AHPP passes the UL-94 V-0 rating without dripping, indicating that the incorporation of AHPP and DOPO can obtain an enormous improvement in flame retardance of EP composites. Obviously, the EP-3 sample has excellent flame retardance, which may further promote the potential application value of EP/DOPO-AHPP with various phosphorus valences.

Table 3. LOI, UL-94 rating, and cone calorimeter data of cured epoxy resin and its composites.

\begin{tabular}{ccccccccc}
\hline Samples & LOI (\%) & UL-94 & $\boldsymbol{t}_{\mathbf{1}} / \boldsymbol{t}_{\mathbf{2}} \mathbf{( s / \mathbf { s } )}$ & PHRR $\left(\mathbf{k W} / \mathbf{m}^{\mathbf{2}}\right)$ & THR $\left.\mathbf{( M J} / \mathbf{m}^{\mathbf{2}}\right)$ & SPR $\left(\mathbf{m}^{\mathbf{2}} / \mathbf{s}\right)$ & CO $\left(\mathbf{m g} / \mathbf{m}^{\mathbf{3}}\right)$ & Residues $(\mathbf{w t .} \%)$ \\
\hline EP-1 & 23.5 & NR & - & 1422 & 111.9 & 0.343 & 2.43 & 4.3 \\
EP-2 & 28.5 & NR & - & 1015 & 72.6 & 0.546 & 3.18 & 14.5 \\
EP-3 & 32 & V-0 & $2.4 / 1.7$ & 578 & 60.9 & 0.295 & 1.59 & 1.36 \\
EP-4 & 31 & V-1 & $6.5 / 8.2$ & 732 & 69.1 & 0.307 & 1.52 & 22.4 \\
EP-5 & 31.5 & V-0 & $1.5 / 4.2$ & 607 & 65.0 & 0.316 & 2.0 \\
EP-6 & 28 & NR & - & 832 & 69.4 & 0.294 & 2.00 & 18.9 \\
\hline
\end{tabular}

Successively, to get further information about the combustion behavior, the combustion process of epoxy thermoset at oxygen concentrations of $23.5 \%$ and $32 \%$ during LOI test was monitored. As depicted in Figure 3c, pristine EP ignites rapidly and burns vigorously over the surface of the thermoset. Contrarily, the incorporation of AHPP and DOPO changes the combustion behavior of EP matrix significantly. EP/DOPO-AHPP exhibited a so-called "blowing-out effect", reflecting in the raised LOI values from $23.5 \%$ up to $32.0 \%$. Besides, EP/DOPO-AHPP forms expandable burning residues during combustion. It is apparent that the flame-retardant system promotes the production of a physical barrier layer, retarding the permeation of heat and oxygen [38]. Accordingly, a favorable synergistic effect for the fire safety of EP/DOPO-AHPP composite is revealed and has been further confirmed.

Cone calorimeter measurement is experimented to reveal the flammability of the polymeric materials in bench-scale measurements [39]. As portrayed in Figure 4a,b and Table 3, pristine epoxy is highly flammable with a peak heat release rate (PHRR) of $1422 \mathrm{~kW} / \mathrm{m}^{2}$. Meanwhile, it is noticeable that several sharp peaks are observed at 100-200 s for pristine epoxy (Figure 4a), which is attributed to the formation of a protective chars [40]. When $5 \mathrm{wt}$. \% AHPP or DOPO is incorporated separately, the PHRR values are decreased dramatically to 1015 and $832 \mathrm{~kW} / \mathrm{m}^{2}$, an approximately $28.6 \%$ and $41.4 \%$ reduction in contrast to pristine EP. A larger reduction (59\%) of PHRR is seen with the simultaneous presence of AHPP and DOPO, exhibiting the potential to achieve better flame retardance. At the end of combustion, pristine epoxy burns fiercely with a total heat value of $111.9 \mathrm{MJ} / \mathrm{m}^{2}$ (Figure $4 \mathrm{~b}$ ) and loses $\sim 95 \%$ of its initial mass. As Figure 4 demonstrates, the addition of $5 \mathrm{wt}$. \% AHPP or DOPO decreases the THR to $69.4 \mathrm{MJ} / \mathrm{m}^{2}$ (EP-AHPP) and $72.6 \mathrm{MJ} / \mathrm{m}^{2}$ (EP/DOPO). It should be highlighted that the simultaneous incorporation of AHPP and DOPO can obviously reduce both PHRR and THR of EP composites when the ratio of DOPO/AHPP is 2:1. Compared with the corresponding samples, the results show that the synergy between AHPP and DOPO reduces the heat release for the epoxy matrix during combustion, which is beneficial for decreasing the thermal hazard.

\subsection{Smoke and Toxicity Hazards Analysis}

Generally, epoxy resin, an organic polymer with an aliphatic and aromatic ring, produces a large amount of toxic fumes (especially $\mathrm{CO}$ ) and smoke production. Accordingly, to meet the demands of reducing the death rate in fire and environmental protection, intensive attention should be focused on eco-friendly flame-retardant additives. Here, Figure 4 gives the combustion parameters and smoke toxicity information of EP composites. Compared to pristine EP, the $\mathrm{CO}$ release and smoke production escaping from the combustion of EP composites have been suppressed by the simultaneous addition of AHPP and DOPO at $5 \mathrm{wt}$ \% loading ( $>40 \%$ reduction for total smoke production (TSP), Figure $4 \mathrm{~d}$ in this research. In detail, the existence of DOPO actually increases the smoke production rate (SPR) and $\mathrm{CO}$ release. Meanwhile, the trend of higher total smoke production (TSP) is obtained for EP/DOPO, signifying that DOPO has a stronger quenching effect in the gaseous phase. The gaseous phase flame-retardant effect leads to incomplete combustion, which implies that the introduction of DOPO 
forces more pyrolysis products of polymer into large-scale smoke particles [19]. In contrast, the increase of residual char for the EP-AHPP sample can suppress the transformation of the matrix to fuel, thus reducing smoke production. The elevated production rates of $\mathrm{CO}$ for $\mathrm{EP} / \mathrm{DOPO}$ signify the enhanced incomplete combustion, and the decreased value of the EP-AHPP composite further represents the stronger suppression of smoke toxicity on the combustion reaction. Especially for EP/DOPO-AHPP, the surprisingly lower smoke toxicity and flame inhibition with the same flame-retardant content testify the distinguished condensed phase and gaseous phase flame-retardant activity on decreasing the fire hazard of cured EP during burning.

(a)

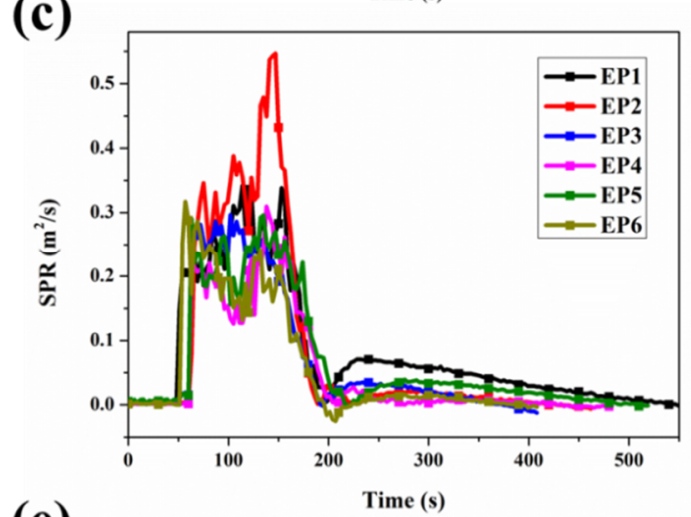

(e)

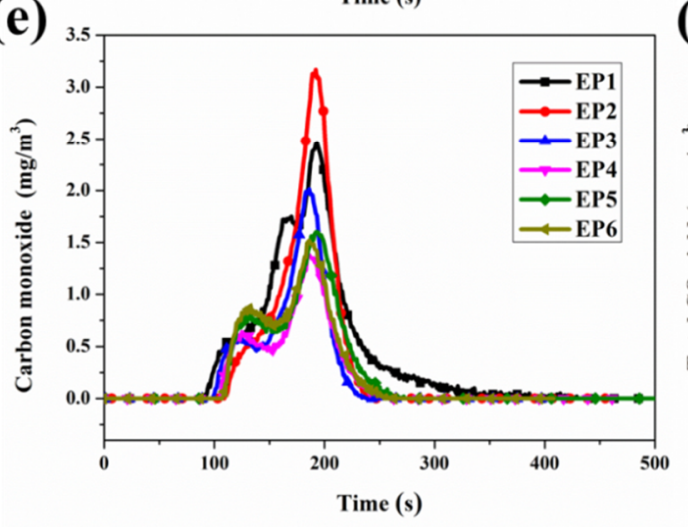

(b)

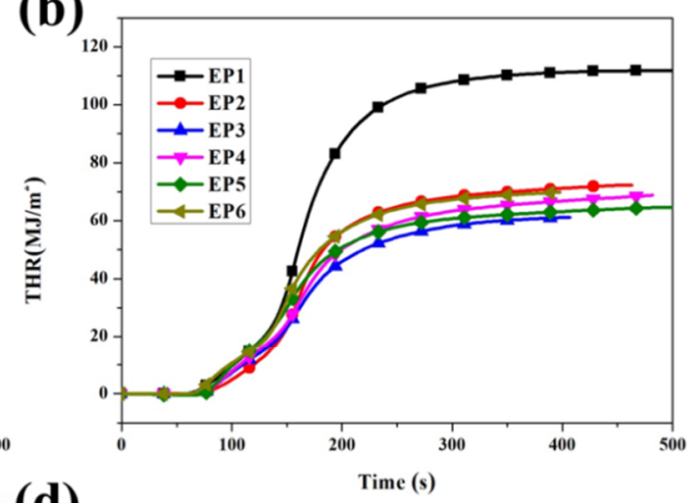

(d)

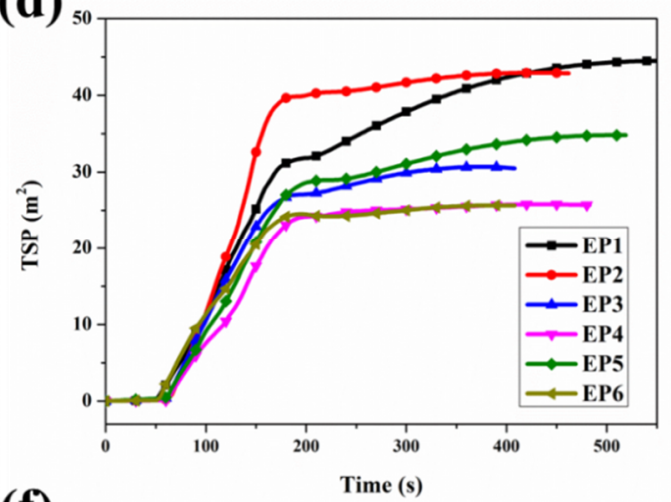

(f)

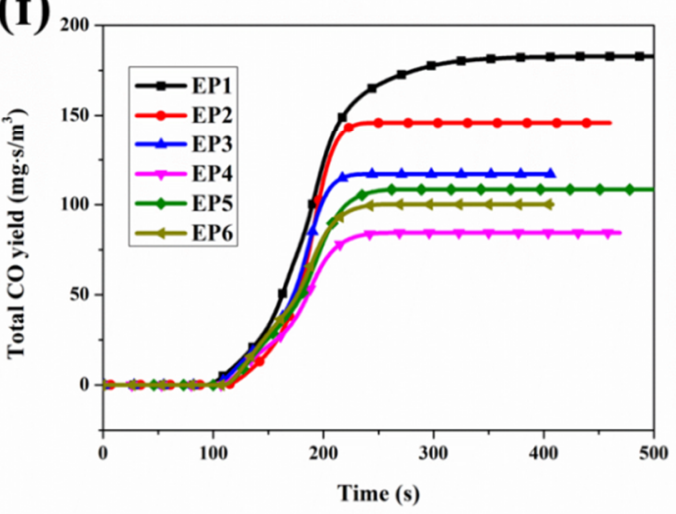

Figure 4. Heat release rate (a), total heat release (b) smoke production rate (SPR) (c), total smoke production (TSP) (d), CO (e), and total CO yield (f) versus temperature curves of pristine EP and its composites from cone test.

To further evaluate the fire safety properties, TG-FTIR measurement was employed to detect the volatile degradation products resulting from EP composites and the absorbance of total pyrolytic gases of EP and EP/DOPO-AHPP composite is displayed in Figure 5. Similar characteristic peaks are clearly distinguished by typical strong FTIR signals: hydroxide groups $\left(3650-3400 \mathrm{~cm}^{-1}\right)$, the vibration absorbance of $\mathrm{C}=\mathrm{O}$ and $\mathrm{C}-\mathrm{O}-\mathrm{C}$ groups $\left(1607,1260 \mathrm{~cm}^{-1}\right)$, and compounds containing aromatic ring 
(1605-1450, 1260-927 $\left.\mathrm{cm}^{-1}\right)$. It shows that the stretching vibrations at 2360 and $2180 \mathrm{~cm}^{-1}$ derived from the formation of $\mathrm{CO}_{2}$ and $\mathrm{CO}$ during decomposition for the epoxy matrix significantly decreases, revealing reduced toxic gases release for EP/DOPO-AHPP.
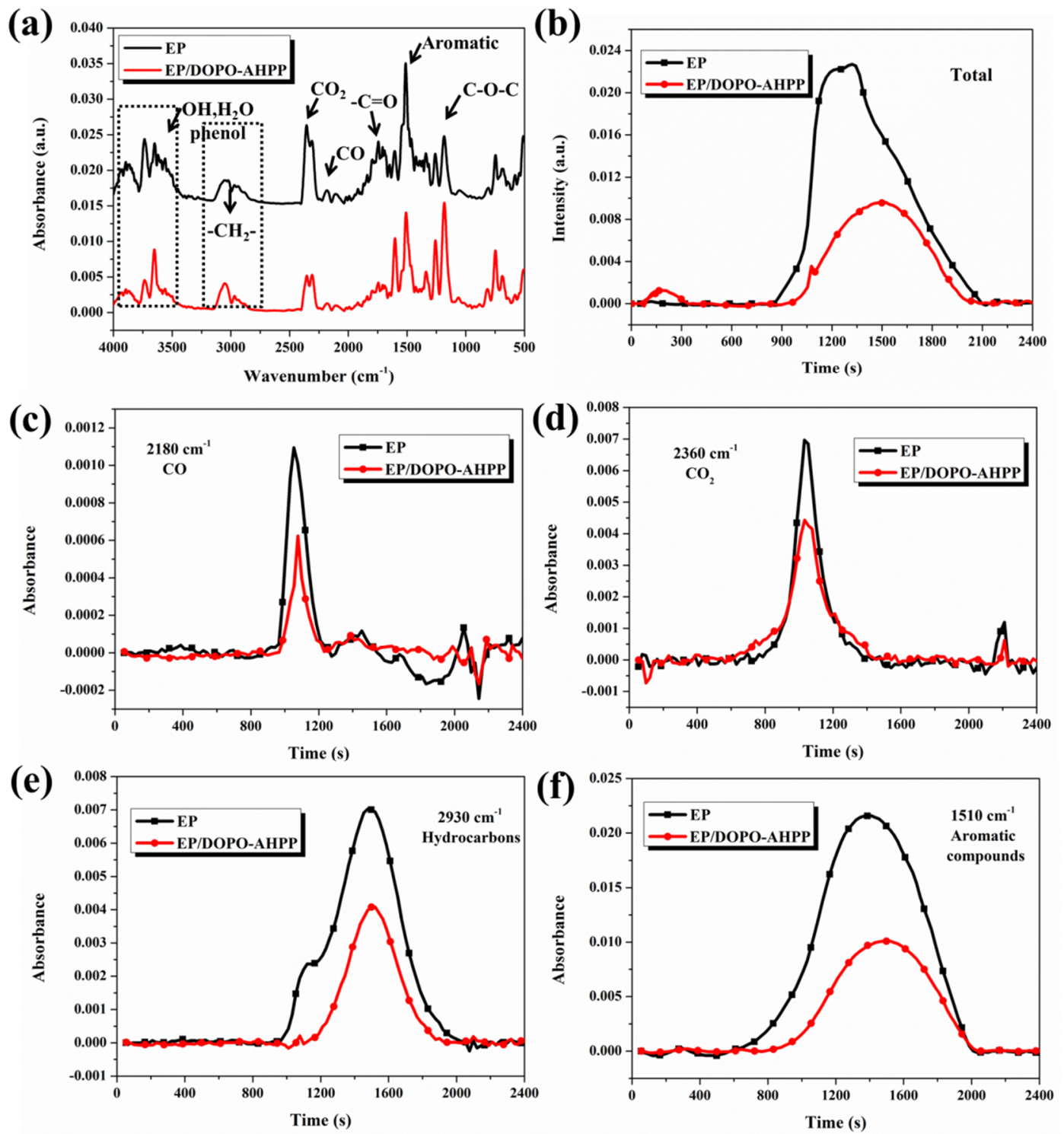

Figure 5. FTIR spectrum of pyrolysis products at the maximum decomposition rate (a); Gram-Schmidt curves (b) and absorbance of pyrolysis products in nitrogen atmosphere for EP and EP-4 versus time. $\mathrm{CO}(\mathbf{c}) ; \mathrm{CO}_{2}(\mathbf{d})$; hydrocarbons (e); and aromatic compounds (f).

To better clarify the smoke toxicity suppression behavior, the FTIR absorbance of volatile degradation products of EP and the EP/DOPO-AHPP composite is displayed in Figure $5 \mathrm{c}-\mathrm{f}$. In comparison with the pristine $\mathrm{EP}$, the absorbance intensity of pyrolytic products of the EP/DOPO-AHPP system is dramatically decreased, which will be aggregated to form smoke [41]. Meanwhile, the reduced CO release and the organic volatiles have been significantly decreased, which further confirms the suppression of smoke and toxicity. According to the above-mentioned facts, a fire hazard suppression mode, with the incorporation of AHPP and DOPO, simultaneously reduces the thermal stability and improve the fire safety for EP composite. 


\subsection{Flame Retardation Mechanism}

The char analysis of EP and its composites from cone tests provide useful feedback about the flame retardation mechanism, including char morphology and structure which are studied in-depth. As expected, pristine EP exhibits a high flammability with visible surface cracks after combustion (Figure S4a, Supplementary Materials). Simultaneously, the presence of AHPP and DOPO can catalyze resin to largely form more stable char. Therefore, the residual char of EP/DOPO-AHPP is much more compact and continuous with fewer cracks and holes than those of other EP composites.

For EP/DOPO-AHPP, incorporating reactive organic and unreactive inorganic additives leads to the construction of a very thick and non-inflammable char layer after burning, due to the catalytic carbonization of flame retardants [42]. As shown in Figure S4g-i (Supplementary Materials), the elemental mapping image shows that $\mathrm{O}, \mathrm{P}$ and $\mathrm{Al}$ elements (i.e., the residual char constituents, apart from C) are homogeneously distributed. Meanwhile, as can be seen in XRD patterns of the char residue, AHPP particles undergo thermal degradation producing $\mathrm{Al}_{2} \mathrm{O}_{3}$ [43] on the epoxy surfaces, which acts as a protective layer as a heat and oxygen shield to reduce the flammable volatiles escaped and improve the fire safety.

To further evaluate the influence of EP/DOPO-AHPP on the char formation during decomposition, the macroscopic view and graphitic structure of the char residues were studied directly by a digital camera and Raman spectroscopy. As portrayed in Figure 6, adding AHPP and DOPO into EP increases the char yield and strength. As is well-known, flame-retardant efficiency is not only dependent on the number of char residues but also their quality [44]. The spectra of char residue exhibit a similar shape including two peaks at 1590 and $1360 \mathrm{~cm}^{-1}$. The peak at $1360 \mathrm{~cm}^{-1}$ is named as D band and the peak at $1590 \mathrm{~cm}^{-1}$ belongs to $\mathrm{G}$ band [45]. Generally, the graphitization degree of char could be calculated by the integrated intensity ratio of $D$ and $G$ bands [46]. The $I_{D} / I_{G}$ value follows the sequence of pristine $\mathrm{EP}(2.81)>\mathrm{EP} / \mathrm{DOPO}$ (2.60) > EP-AHPP (2.58) > EP/DOPO-AHPP (2.57). Therefore, adding AHPP and DOPO could accelerate amorphous char into the graphitic structure during burning, achieving an ideal physical barrier of the EP composites.
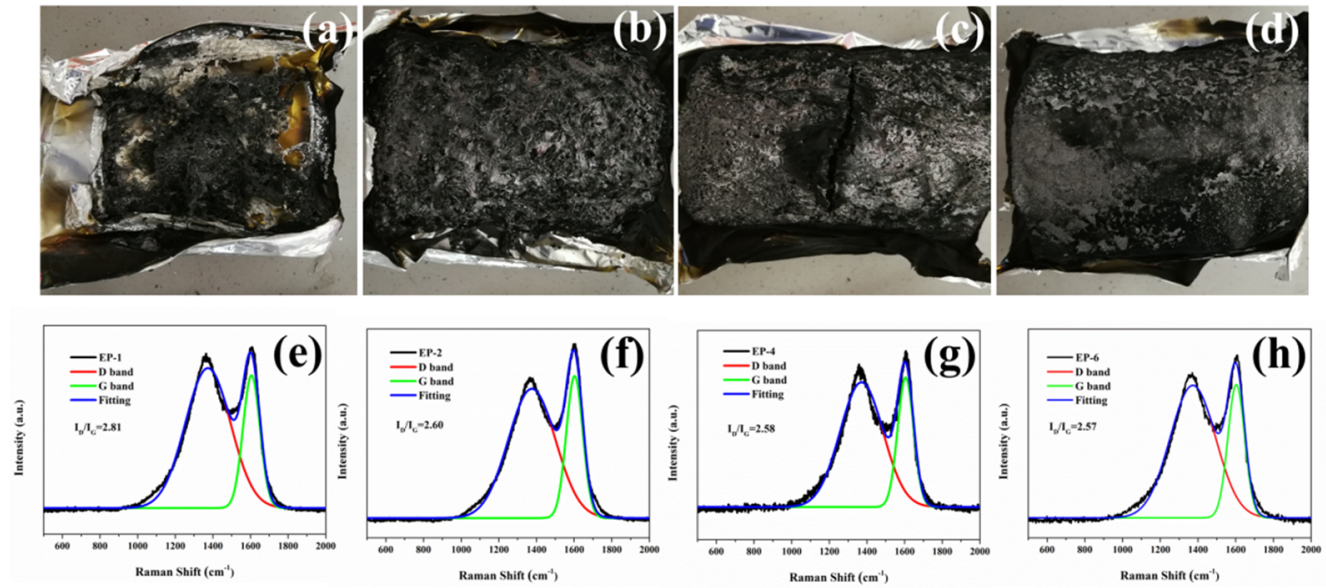

Figure 6. Photographs and Raman spectra of the char residue from pristine EP (a,e), EP/DOPO (b,f), EP/DOPO-AHPP (c,g), and EP-AHPP (d,h) after cone calorimeter tests.

From Figure 7 , the peaks in the range of $1550-750 \mathrm{~cm}^{-1}$ which can be assigned to $\mathrm{O}=\mathrm{P}-\mathrm{O}-, \mathrm{P}-\mathrm{O}-\mathrm{C}$, and P-O-P vibrations in the FTIR spectra [36]. Additionally, the spectra exhibit a peak at $817 \mathrm{~cm}^{-1}$ distinctly, signifying that the presence of AHPP and DOPO can promote resin to form the aromatic structure and phosphorus-rich char during decomposition. 

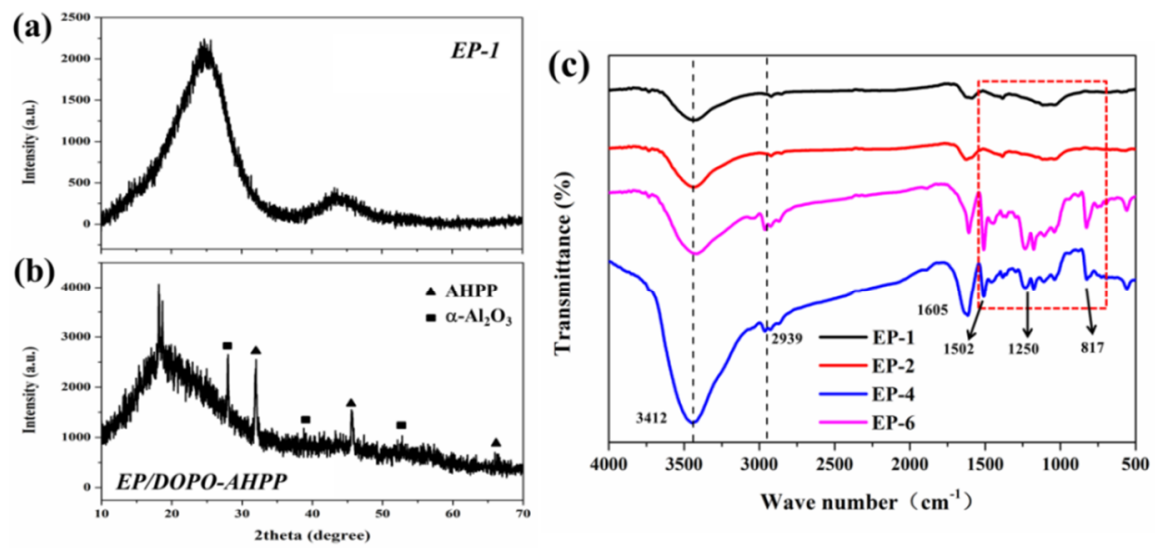

Figure 7. XRD patterns and FTIR spectra of the char residue of pristine EP and its composites from cone test.

Based on the analysis above, for EP/DOPO-AHPP ternary, the PHRR, THR, and both TSP and toxic $\mathrm{CO}$ are considerably decreased. The integrity of char residue is increased, and the phosphorus-containing moieties remain in the condensed phase, suggesting that combustible volatiles release and smoke toxicity is suppressed distinctly. As shown in Figure 8, the generation of residual char with $\mathrm{Al}_{2} \mathrm{O}_{3}$ layer covering on the epoxy surfaces performs a stronger barrier action to protect the EP matrix with the simultaneous addition of AHPP and DOPO. In the gaseous phase, the notable phenomenon is the generation of a so-called "blowing-out effect", which is consistent with the above-mentioned combustion process and in accordance with previous reports [33,47]. It is noteworthy that the enormous improvement in fire safety for the EP/DOPO-AHPP composites, derived from LOI, UL-94, and cone calorimeter results, are probably connected with the continuous and compact residues, which can avoid oxygen from feeding the fire and inhibit the release of flammable gas, thus resulting in the relatively low THR and TSP of EP/DOPO-AHPP [48]. Therefore, the condensed mechanism and gaseous mechanism for flame retardance and smoke toxicity suppression between AHPP and DOPO are verified, and the former one is dominant in EP/DOPO-AHPP composites.

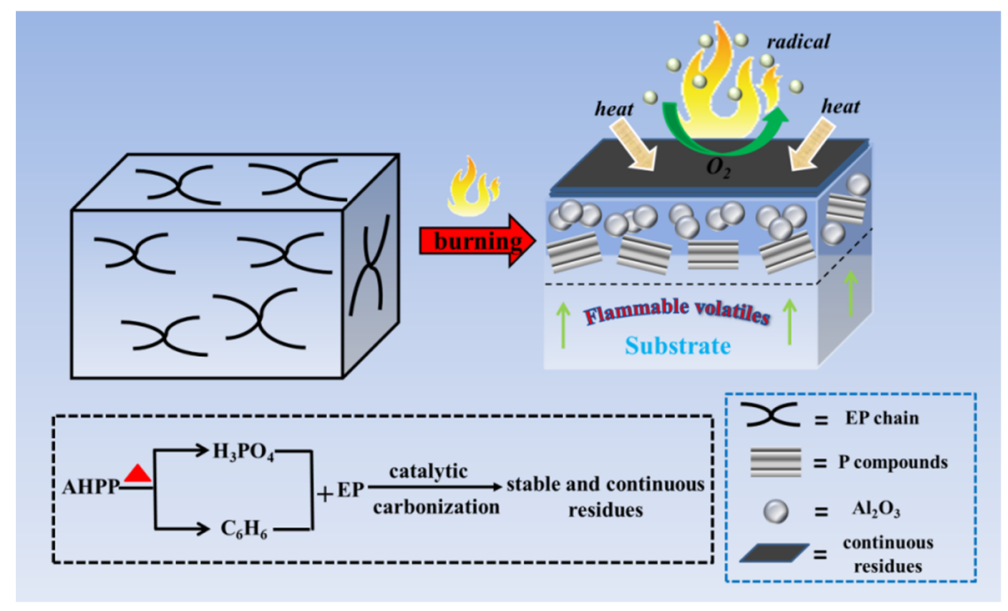

Figure 8. Illustration of the mechanism for the enhanced flame retardance and smoke toxicity suppression of EP/DOPO-AHPP composite.

\section{Conclusions}

A fire hazard suppression mode containing phosphorus oxidation states of $-1,+1$, and +3 through the incorporation of reactive organic and unreactive inorganic additives was successfully applied to EP, resulting in the construction of a very thick and non-inflammable char layer and tremendous reduction 
of TSP and toxic CO during combustion. Novel flame-retardant particles were successfully prepared via polycondensation. The submicro-scaled structure of this phosphorus-containing flame-retardant endows resultant EP with excellent smoke hazard suppression property. The incorporation of AHPP and DOPO into EP catalyzed and accelerated the formation of protective barrier char layers, compared with the thermosets filled with AHPP or DOPO individually at a same mass fraction. Notably, with a much higher isolating effect on combustible volatiles, oxygen, and heat than independently produced chemical chars in this fire hazard suppression mode, the EP/DOPO-AHPP system displayed dramatically higher flame retardance and smoke suppression properties, including LOI, UL-94 rating, and cone calorimeter results. All the results showed that the sample EP-3 with the DOPO/AHPP ratio of 2:1 endowed the EP composites with the most satisfying flame-retardant performance, and the later one with the ratio of 1:2 exhibited a better efficiency of smoke toxicity suppression. As a result, this fire hazard suppression mode exhibits an efficient approach for enhancing the fire safety of thermoset polymers with high performance.

Supplementary Materials: The following are available online at http://www.mdpi.com/2073-4360/12/1/64/s1, Figure S1: The 1H NMR spectrum (a) and 31P NMR spectrum (b) of HPP with DMSO-d6 as the solvent, Figure S2: SEM observations of submicro-scaled AHPP: low-magnification (a) and magnified image (b), Figure S3: TEM image (a) and EDX spectrum (b) of submicro-scaled AHPP, Figure S4: SEM micrographs of the char residue of pristine EP $(a, b), E P / D O P O-A H P P ~(c, d)$, and EP-AHPP $(e, f)$, and elemental distribution from EDX mapping of the EP-AHPP composite (g-i), Table S1: Assignments of the peaks in FTIR spectra of cured epoxy resin and its composites.

Author Contributions: Y.Y. made the investigation and wrote the original draft. B.Y. performed the methodology and formal analysis. W.W. and Y.L. are the corresponding authors. W.W. and Y.L. performed the project administration and carefully made the investigation. L.M. and J.X. assisted the experimental operation. H.P. assisted the characterization of samples. Y.S. assisted the improvement of language through the manuscript. All authors checked the manuscript.

Funding: The work was financially supported by Australian Research Council Discovery Early Career Research Award (DE190101176), National Natural Science Foundation of China (51703208) and Natural Science Foundation of Hunan province, China (2019JJ50132) and High-Level Talents Support Plan of Xiamen University of Technology, China (YKJ19008R) and Young and Middle-aged Teachers Education Scientific Research Project of Fujian Province (JAT170403).

Acknowledgments: The authors sincerely thank Ying Pan for assisted analysis of Raman spectra and TEM images.

Conflicts of Interest: The authors declare no conflicts of interest.

\section{References}

1. Gu, H.; Ma, C.; Gu, J.; Guo, J.; Yan, X.; Huang, J.; Zhang, Q.; Guo, Z. An overview of multifunctional epoxy nanocomposites. J. Mater. Chem. C 2016, 4, 5890-5906. [CrossRef]

2. Wang, S.; Ma, S.; Xu, C.; Liu, Y.; Dai, J.; Wang, Z.; Liu, X.; Chen, J.; Shen, X.; Wei, J. Vanillin-derived high-performance flame retardant epoxy resins: Facile synthesis and properties. Macromolecules 2017, 50, 1892-1901. [CrossRef]

3. Auvergne, R.; Caillol, S.; David, G.; Boutevin, B.; Pascault, J.P. Biobased thermosetting epoxy: Present and future. Chem. Rev. 2013, 114, 1082-1115. [CrossRef] [PubMed]

4. Yang, S.; Wang, J.; Huo, S.; Wang, M.; Cheng, L. Synthesis of a phosphorus/nitrogen-containing additive with multifunctional groups and its flame-retardant effect in epoxy resin. Ind. Eng. Chem. Res. 2015, 54, 7777-7786. [CrossRef]

5. You, G.; Cheng, Z.; Tang, Y.; He, H. Functional group effect on char formation, flame retardancy and mechanical properties of phosphonate-triazine-based compound as flame retardant in epoxy resin. Ind. Eng. Chem. Res. 2015, 54, 7309-7319. [CrossRef]

6. Wan, J.; Li, C.; Bu, Z.Y.; Xu, C.J.; Li, B.G.; Fan, H. A comparative study of epoxy resin cured with a linear diamine and a branched polyamine. Chem. Eng. J. 2012, 188, 160-172. [CrossRef]

7. Jian, R.; Wang, P.; Duan, W.; Wang, J.; Zheng, X.; Weng, J. Synthesis of a novel P/N/S-containing flame retardant and its application in epoxy resin: Thermal property, flame retardance, and pyrolysis behavior. Ind. Eng. Chem. Res. 2016, 55, 11520-11527. [CrossRef] 
8. Wan, J.; Gan, B.; Li, C.; Molina-Aldareguia, J.; Li, Z.; Wang, X.; Wang, D.Y. A novel biobased epoxy resin with high mechanical stiffness and low flammability: Synthesis, characterization and properties. J. Mater. Chem. A 2015, 3, 21907-21921. [CrossRef]

9. Starost, K.; Frijns, E.; Van Laer, J.; Faisal, N.; Egizabal, A.; Elizextea, C.; Blazquez, M.; Nelissen, I.; Njuguna, J. Assessment of nanoparticles release into the environment during drilling of carbon nanotubes/epoxy and carbon nanofibres/epoxy nanocomposites. J. Hazard. Mater. 2017, 340, 57-66. [CrossRef]

10. Yu, B.; Shi, Y.; Yuan, B.; Qiu, S.; Xing, W.; Hu, W.; Song, L.; Lo, S.; Hu, Y. Enhanced thermal and flame retardant properties of flame-retardant-wrapped graphene/epoxy resin nanocomposites. J. Mater. Chem. A 2015, 3, 8034-8044. [CrossRef]

11. Wang, W.; Kan, Y.; Liu, J.; Liew, K.M.; Liu, L.; Hu, Y. Self-assembly of zinc hydroxystannate on amorphous hydrous $\mathrm{TiO}_{2}$ solid sphere for enhancing fire safety of epoxy resin. J. Hazard. Mater. 2017, 340, $263-271$. [CrossRef] [PubMed]

12. Sun, J.; Wang, X.; Wu, D. Novel spirocyclic phosphazene-based epoxy resin for halogen-free fire resistance: Synthesis, curing behaviors, and flammability characteristics. ACS Appl. Mater. Interfaces 2012, 4, 4047-4061. [CrossRef] [PubMed]

13. Allauddin, S.; Narayan, R.; Raju, K. Synthesis and properties of alkoxysilane castor oil and their polyurethane/urea-silica hybrid coating films. ACS Sustain. Chem. Eng. 2013, 1, 910-918. [CrossRef]

14. Jiang, J.; Cheng, Y.; Liu, Y.; Wang, Q.; He, Y.; Wang, B. Intergrowth charring for flame-retardant glass fabric-reinforced epoxy resin composites. J. Mater. Chem. A 2015, 3, 4284-4290. [CrossRef]

15. Chen, X.; Ye, J.; Yuan, L.; Liang, G.; Gu, A. Multi-functional ladderlike polysiloxane: Synthesis, characterization and its high performance flame retarding bismaleimide resins with simultaneously improved thermal resistance, dimensional stability and dielectric properties. J. Mater. Chem. A 2014, 2, 7491-7501. [CrossRef]

16. Shi, Y.; Yu, B.; Duan, L.; Gui, Z.; Wang, B.; Hu, Y.; Yuen, R.K. Graphitic carbon nitride/phosphorus-rich aluminum phosphinates hybrids as smoke suppressants and flame retardants for polystyrene. J. Hazard. Mater. 2017, 332, 87-96. [CrossRef]

17. Perret, B.; Schartel, B.; Stöß, K.; Ciesielski, M.; Diederichs, J.; Döring, M.; Krämer, J.; Altstädt, V. A New Halogen-Free Flame Retardant Based on 9, 10-Dihydro-9-oxa-10-vphosphaphenanthrene-10-oxide for Epoxy Resins and their Carbon Fiber Composites for the Automotive and Aviation Industries. Macromol. Mater. Eng. 2011, 296, 14-30. [CrossRef]

18. Müller, P.; Bykov, Y.; Döring, M. New star-shaped phosphorus-containing flame retardants based on acrylates for epoxy resins. Polym. Adv. Technol. 2013, 24, 834-840. [CrossRef]

19. Qiu, Y.; Liu, Z.; Qian, L.; Hao, J. Pyrolysis and flame retardant behavior of a novel compound with multiple phosphaphenanthrene groups in epoxy thermosets. J. Anal. Appl. Pyrolysis 2017, 127, 23-30. [CrossRef]

20. Braun, U.; Balabanovich, A.I.; Schartel, B.; Knoll, U.; Artner, J.; Ciesielski, M.; Döring, M.; Perez, R.; Sandler, J.K.; Altstädt, V. Influence of the oxidation state of phosphorus on the decomposition and fire behaviour of flame-retarded epoxy resin composites. Polymer 2006, 47, 8495-8508. [CrossRef]

21. Mariappan, T.; Zhou, Y.; Hao, J.; Wilkie, C.A. Influence of oxidation state of phosphorus on the thermal and flammability of polyurea and epoxy resin. Eur. Polym. J. 2013, 49, 3171-3180. [CrossRef]

22. Huang, L.; Li, Y.; Yang, J.; Zeng, Z.; Chen, Y. Self-initiated photopolymerization of hyperbranched acrylates. Polymer 2009, 50, 4325-4333. [CrossRef]

23. Liu, J.; Huang, W.; Zhou, Y.; Yan, D. Synthesis of hyperbranched polyphosphates by self-condensing ring-opening polymerization of HEEP without catalyst. Macromolecules 2009, 42, 4394-4399. [CrossRef]

24. Wang, D.; Zheng, Z.; Hong, C.; Liu, Y.; Pan, C. Michael addition polymerizations of difunctional amines $\left(\mathrm{AA}^{\prime}\right)$ and triacrylamides $\left(\mathrm{B}_{3}\right)$. J. Polym. Sci. Part A Polym. Chem. 2006, 44, 6226-6242. [CrossRef]

25. Yang, W.; Yuen, R.K.; Hu, Y.; Lu, H.; Song, L. Development and characterization of fire retarded glass-fiber reinforced poly (1, 4-butylene terephthalate) composites based on a novel flame retardant system. Ind. Eng. Chem. Res. 2011, 50, 11975-11981. [CrossRef]

26. Pinto, U.A.; Visconte, L.L.Y.; Nunes, R.C.R. Mechanical properties of thermoplastic polyurethane elastomers with mica and aluminum trihydrate. Eur. Polym. J. 2001, 37, 1935-1937. [CrossRef] 
27. Yuan, Y.; Shi, Y.; Yu, B.; Zhan, J.; Zhang, Y.; Song, L.; Ma, C.; Hu, Y. Facile synthesis of aluminum branched oligo (phenylphosphonate) submicro-particles with enhanced flame retardance and smoke toxicity suppression for epoxy resin composites. J. Hazard. Mater. 2020, 381, 121233. [CrossRef]

28. Xie, J.; Hu, L.; Shi, W.; Deng, X.; Cao, Z.; Shen, Q. Synthesis and characterization of hyperbranched polytriazole via an ' $\mathrm{A}_{2}+\mathrm{B}_{3}$ 'approach based on click chemistry. Polym. Int. 2008, 57, 965-974. [CrossRef]

29. Daasch, L.; Smith, D. Infrared spectra of phosphorus compounds. Anal. Chem. 1951, 23, 853-868. [CrossRef]

30. Yuan, Y.; Yang, H.; Yu, B.; Shi, Y.; Wang, W.; Song, L.; Hu, Y.; Zhang, Y. Phosphorus and nitrogen-containing polyols: Synergistic effect on the thermal property and flame retardancy of rigid polyurethane foam composites. Ind. Eng. Chem. Res. 2016, 55, 10813-10822. [CrossRef]

31. Wang, Q.; Shi, W. Photopolymerization and thermal behaviors of acrylated benzenephosphonates/epoxy acrylate as flame retardant resins. Eur. Polym. J. 2006, 42, 2261-2269. [CrossRef]

32. Xu, W.; Wirasaputra, A.; Liu, S.; Yuan, Y.; Zhao, J. Highly effective flame retarded epoxy resin cured by DOPO-based co-curing agent. Polym. Degrad. Stab. 2015, 122, 44-51. [CrossRef]

33. Perret, B.; Schartel, B.; Stöß, K.; Ciesielski, M.; Diederichs, J.; Döring, M.; Krämer, J.; Altstädt, V. Novel DOPO-based flame retardants in high-performance carbon fibre epoxy composites for aviation. Eur. Polym. J. 2011, 47, 1081-1089. [CrossRef]

34. Xiao, J.; Hu, Y.; Yang, L.; Cai, Y.; Song, L.; Chen, Z.; Fan, W. Fire retardant synergism between melamine and triphenyl phosphate in poly (butylene terephthalate). Polym. Degrad. Stab. 2006, 91, 2093-2100. [CrossRef]

35. Wang, G.A.; Cheng, W.M.; Tu, Y.L.; Wang, C.C.; Chen, C.Y. Characterizations of a new flame-retardant polymer. Polym. Degrad. Stab. 2006, 91, 3344-3353. [CrossRef]

36. Liu, C.; Chen, T.; Yuan, C.; Song, C.; Chang, Y.; Chen, G.; Xu, Y.; Dai, L. Modification of epoxy resin through the self-assembly of a surfactant-like multi-element flame retardant. J. Mater. Chem. A 2016, 4, 3462-3470. [CrossRef]

37. Xi, W.; Qian, L.; Chen, Y.; Wang, J.; Liu, X. Addition flame-retardant behaviors of expandable graphite and [bis (2-hydroxyethyl) amino]-methyl-phosphonic acid dimethyl ester in rigid polyurethane foams. Polym. Degrad. Stab. 2015, 122, 36-43. [CrossRef]

38. Cao, Y.; Feng, J.; Wu, P. Preparation of organically dispersible graphene nanosheet powders through a lyophilization method and their poly (lactic acid) composites. Carbon 2010, 48, 3834-3839. [CrossRef]

39. Liu, L.; Wang, Z. Facile synthesis of a novel magnesium amino-tris-(methylenephosphonate)-reduced graphene oxide hybrid and its high performance in mechanical strength, thermal stability, smoke suppression and flame retardancy in phenolic foam. J. Hazard. Mater. 2018, 357, 89-99. [CrossRef]

40. Schartel, B.; Hull, T.R. Development of fire-retarded materials-Interpretation of cone calorimeter data. Fire. Mater. 2007, 31, 327-354. [CrossRef]

41. Feng, X.; Xing, W.; Song, L.; Hu, Y. In situ synthesis of a $\mathrm{MoS}_{2} / \mathrm{CoOOH}$ hybrid by a facile wet chemical method and the catalytic oxidation of CO in epoxy resin during decomposition. J. Mater. Chem. A 2014, 2, 13299-13308. [CrossRef]

42. Wang, X.; Xing, W.; Feng, X.; Yu, B.; Song, L.; Hu, Y. Functionalization of graphene with grafted polyphosphamide for flame retardant epoxy composites: Synthesis, flammability and mechanism. Polym. Chem. 2014, 5, 1145-1154. [CrossRef]

43. Feng, Y.; Hu, J.; Xue, Y.; He, C.; Zhou, X.; Xie, X.; Ye, Y.; Mai, Y.W. Simultaneous improvement in the flame resistance and thermal conductivity of epoxy/ $\mathrm{Al}_{2} \mathrm{O}_{3}$ composites by incorporating polymeric flame retardant-functionalized graphene. J. Mater. Chem. A 2017, 5, 13544-13556. [CrossRef]

44. Wawrzyn, E.; Schartel, B.; Ciesielski, M.; Kretzschmar, B.; Braun, U.; Döring, M. Are novel aryl phosphates competitors for bisphenol A bis (diphenyl phosphate) in halogen-free flame-retarded polycarbonate/acrylonitrile-butadiene-styrene blends? Eur. Polym. J. 2012, 48, 1561-1574. [CrossRef]

45. Yu, B.; Tawiah, B.; Wang, L.Q.; Yuen, A.C.Y.; Zhang, Z.C.; Shen, L.L.; Lin, B.; Fei, B.; Yang, W.; Li, A. Interface decoration of exfoliated MXene ultra-thin nanosheets for fire and smoke suppressions of thermoplastic polyurethane elastomer. J. Hazard. Mater. 2019, 374, 110-119. [CrossRef] 
46. Yuan, Y.; Wang, W.; Shi, Y.; Song, L.; Ma, C.; Hu, Y. The influence of highly dispersed $\mathrm{Cu}_{2} \mathrm{O}$-anchored $\mathrm{MoS}_{2}$ hybrids on reducing smoke toxicity and fire hazards for rigid polyurethane foam. J. Hazard. Mater. 2019, 382, 121028. [CrossRef]

47. Schartel, B.; Braun, U.; Balabanovich, A.; Artner, J.; Ciesielski, M.; Döring, M.; Perez, R.; Sandler, J.; Altstädt, V. Pyrolysis and fire behaviour of epoxy systems containing a novel 9, 10-dihydro-9-oxa-10-phosphaphenanthrene-10-oxide-(DOPO)-based diamino hardener. Eur. Polym. J. 2008, 44, 704-715. [CrossRef]

48. Yu, L.; Chen, L.; Dong, L.P.; Li, L.J.; Wang, Y.Z. Organic-inorganic hybrid flame retardant: Preparation, characterization and application in EVA. RSC Adv. 2014, 4, 17812-17821. [CrossRef]

(C) 2020 by the authors. Licensee MDPI, Basel, Switzerland. This article is an open access article distributed under the terms and conditions of the Creative Commons Attribution (CC BY) license (http://creativecommons.org/licenses/by/4.0/). 